GLOBAL JOURNAL OF SOCIAL SCIENCES VOL 20, 2021: 87-97 COPYRIGHTC BACHUDO SCIENCE CO. LTD PRINTED IN NIGERIA. ISSN 1596-6216 WwW.globaljournalseries.com; globaljournalseries@gmail.com

\title{
APPLICABILITY OF EMERGENCY MANAGEMENT THEORY IN THE MANAGEMENT OF COVID-19 HEALTH PANDEMIC IN NIGERIA
}

UGHULU, EGHOIKHUNU STELLA AND IGABOR, OBAREN THOMAS

(Received 7 June 2021, Revision Accepted 4 August 2021 2021)

\begin{abstract}
Emergency has become a global reoccurrence and when it occurs in a country, the government usually adopt measures to curtail the negative effects of the phenomenon. COVID-19 as the present global emergency needs to be tackled with proper and effective management measures. The principles of Emergency Management Theory are among the global highly rated and most common measures used to tackle emergencies to achieve minimal effect on lives and economies. It is based on the above statements that this study examined the Application of the principles of Emergency Management Theory in the Federal Government of Nigeria's management of COVID-19 to ascertain the extent the Federal Government is utilizing the theory's principles in its fight against COVID-19 in Nigeria. The study utilized the secondary method of data collection and used observations and documents as its tools of evaluation. The study found that the principles of Emergency Management Theory have been applied by the Federal Government in the management of COVID-19 in Nigeria. The study concludes that the application of the principles Emergency Management Theory in the management of COVID-19 has greatly enhanced Government's efforts in the fight against the disease in Nigeria. To improve on emergency management in Nigeria, the study recommended that: Individual researchers and research institutes be supported to develop more proactive ways of dealing with emergencies in the country and Nigerians should all be re-orientated and sensitized on how to prevent, respond and deal with emergencies.
\end{abstract}

Word Count: 238

KEYWORDS: Emergency, Disaster, Emergency Management Theory, COVID-19 and Federal Government.

\section{INTRODUCTION}

Emergency have become a recurring decimal in many parts of the world. Emergency is any unplanned event that can cause death or significant injury to anyone. It can disrupt, cause physical or environmental damage and financial threat to lives and economies. Emergencies are phenomena that occur globally at various times, whether severe or mild, they need proper management to minimize their effects on human existence.

When an emergency occurs in a country, the government usually adopt measures to curtail the negative effects of the phenomenon. The severity or otherwise of the effects of national emergencies, most times depends on how the government and people react or respond to

Ughulu, Eghoikhunu Stella, Department of Political Science and Public Administration Igbinedion University, Okada, Edo State

Igabor, Obaren Thomas, Department of Public Administration University of Benin, Benin City, Edo State

(C) 2021 Bachudo Science Co. Ltd. This work is licensed under Creative Commons Attribution 4.0 International license. 
emergencies. There have been emergencies such as, plane crashes, road traffic accidents, industrial accidents, ship wrecks, terrorism, war, floods, earthquakes, disease outbreaks, explosions, civil disturbances, etc. Emergency is interchangeable with disaster in this study.

The import of national emergency whether natural disasters or man-made as in wars, are the human suffering that an emergency can cause. At the end of the day, the management of national emergency becomes concerned not just with rebuilding infrastructure damaged, but also with containment of human suffering as a result of these situations. People who are rendered homeless or are pushed out of their homelands as a result of emergency situations become refugees. They have to be properly managed and stabilized. The management of national emergency also involves proactive measures to prepare so as to minimize the effects of the negative consequences of disasters.

There is presently a global emergency, which is a disease outbreak called COVID-19. Governments all over the world are engaged in various measures to manage their economy and citizens to minimize the effects of COVID-19. In the same vein the Nigeria Federal Government has engaged several strategies to manage its economy and citizens to minimize the negative effects of COVID-19.

The principles of Emergency Management Theory are among the global highly rated and most common measures, used for effective management of emergencies to achieve minimal effect on lives and economies. The present global emergency known as COVID-19 needs optimum measures to tackle and minimize its negative effects globally. It is based on the above statements this study examined the applicability of Emergency Management Theory in the management of COVID-19 in the country to ascertain if and how the Government is utilizing the theory's principles in its fight against the disease in Nigeria.

The main objective of this study is to examine the application of the Emergency Management Theory Principles in Federal Government's strategies of managing COVID-19 in Nigeria. The other objectives are to enable the readers know the loopholes of the Emergency Management Theory and how to improve on these loopholes. To achieve the above objectives, the following questions were answered:

i. What are the principles of the Emergency Management theory? ii. How are these principles applied in the Federal Government's strategies of managing COVID-19 in Nigeria?

iii. What are the loopholes of Emergency Management Theory?

iv. What should be done to improve on the loopholes as well as its utilization value in mitigating the effects of emergencies?

The methodology adopted in this study followed the qualitative approach of desk research, entailing a review of literatures relating to the concepts of Emergency Management and COVID-19. The secondary data (internet, published articles, and books) was relied on as the technique for extracting information relevant to the thematic aspects of this study. Qualitative desk evaluation and observations were utilized to analyse the data collected based on which conclusions were drawn and recommendations made.

\section{CONCEPTUAL CLARIFICATION/LITERATURE REVIEW EMERGENCY}

An emergency is any unplanned event that can cause deaths or significant injuries to the public; or that can disrupt operations, cause physical or environmental damage, or threaten the financial standing of businesses and institutions (Udouko, 2017). According to Cambridge Dictionary (2020), an emergency is a dangerous or serious situation, such as an accident, that happens suddenly or unexpectedly and needs immediate action.

As a concept, WHO (2020) defined emergency as an occurrence disrupting the normal conditions of existence and causing a level of suffering that exceeds the capacity of adjustment of the affected community. Impliedly, it concerns itself with events or hazards which have the tendency of causing vulnerability.

In the words of Sinha \& Srivastava (2017), emergencies are sudden, adverse, unfortunate, extreme events or hazards which cause great damage to human beings as well as plants and animals. This is to say that disasters are relatively hazardous in nature.

In light of the above emergency is conceptualized as an unexpected event which causes great loss to life and property. It threatens both normal life and the process of development, and as well cause sudden violence, deaths, destruction of means of livelihood, destruction of hopes and dreams, destruction of structures and displacement of people.

Emergency Management 
Emergency management is defined as the actions taken by an organization in response to unexpected events that are adversely affecting people or resources and threatening the continued operation of the organization (Ezenyilimba, Maduagwu and Eze, 2018). It includes the development of emergency recovery plans, minimizing the risk of disasters and the implementation of such plans that hinge on disaster. With the uprising of different natures of disasters such as flooding, building collapse, road accidents, pipeline explosions, epidemics, bomb blasts, terrorism and inter-communal clashes marking different societies in the world, which is not only interrupting development but also causing severe human survival damages, different countries of the world are seen employing every alternative measure to either prevent their occurrence or tame their effects. This is what emergency management is all about. It encompasses crisis management, contingency or emergency management and risk management by an individual, group, organization or even government.

In the words of Haddow and Bullock (2013), emergency management is nothing but strategic planning and procedure employed to protect critical infrastructures (critical assets) from severe damages when natural or human made calamities and catastrophic events occur. The implication of this purview is that the focus of emergency management is on safeguarding the infrastructural facilities of the people and the society. However, it is paramount to note that disasters are basically affective to humans and their environment and those infrastructures are also man-made. Hence, the focus of emergency management is beyond the safeguard of infrastructures. It went all out to include the safeguard of man and his environment from hazardous externalities either by preventive or palliative measure.

Emergency management is the activities of dealing with and avoiding risks, particularly those that have catastrophic consequences for communities, regions, or entire countries. It is the dynamic process of preparing for, mitigating, responding to and recovering from an emergency (Khorram-Manesh, 2017).

From the foregoing, emergency management is conceptualized as a coordinated process and strategy geared towards preventing the occurrence of an emergency or reducing its impacts on the people and the environment, should it occur. This process or strategy can be initiated whenever anything threatens to put human survival at risk.

COVID-19 Pandemic As An Emergency

According to World Health Organization (WHO) (2020), COVID-19 also referred to as Coronavirus disease 2019 is an illness caused by a novel coronavirus now called severe acute respiratory syndrome coronavirus 2 (SARS-CoV2; formerly called 2019-nCoV). The World Health Organization (WHO) in her Situation Report 22 of 11th February 2020, officially named the 2019 novel coronavirus (2019-nCoV) as COVID-19 (WHO, 2020). The contraction (COVID-19) had to be adopted by WHO to circumvent branding the virus with its first place of identification which is China (WHO, 2020). On March 112020 the WHO declared COVID-19 a pandemic, having met the epidemiological criteria of having infected $>100,000$ people in at least 100 countries (Callaway, 2020).

Mackenzie and Smith (2020), asserted that COVID-19 is an on-going pandemic that started as an outbreak and was epidemiologically linked to a wet animal whole sale market in Wuhan City, China. Similarly, Ogbonna (2020) stated that coronavirus is less severe than the SARS outbreak in 2003 with mortality rate of $2-3 \%$. COVID-19 is a pandemic that has created a global widespread panic posing health, socioeconomic and political challenges such as drifting nations' economy into recession, reducing democratic and participatory governance, reduction in social relations a result of the social distancing, movement restriction and lock-down policies among others (Yemisi, 2020).

Presently, there is no official curative medicine but vaccines have been recently developed against the disease (vaccinateyourfamily, 2021). Nevertheless, people are advised by medical experts to maintain general good hygiene like washing of hands frequently, sanitizing of hands, and avoidance of crowded places, people are advised most times to stay indoors (WHO, 2020). COVID-19 is a disaster emergency because the disease conforms to key baseline conclusions which have emerged from disaster anthropology over past decades. First, that natural disasters rarely exist, because disasters are social, arising from a combination of hazard and vulnerability, with vulnerability as the causative factor. Second, that disaster occurs at multiple levels simultaneously, with responses to a hazard exposing as many vulnerability problems as the original hazard (Kelman, 2020). 


\section{EMERGENCY MANAGEMENT THEORY}

Emergency Management Theory is a theory of disaster and risk management propounded in 2004 by an American expert in Emergency Administration by name David McEntire. This theory was formulated in a bid to provide a pragmatic, proactive and reactive all-in-one paradigm for management of disruptive and hazardous phenomena after the terrorist attacks on the Pentagon and World Trade Centre on 11 September, 2001 in United States of America.

This theory holds that disastrous emergencies are inevitable in the society and have the tendency of causing unrecoverable effects unless responsible, immediate and urgent measures are taken in the dimension of preventing, responding, recovering and mitigating issues of these emergencies. It states that unless these measures and the strategies of executing them are put in place, the society is doomed to be marred by unrecoverable emergency situations that will threaten its existence. The theory also holds that if the human species and society do not want to be likened to the extinct animal species, then they should evolve proactive, reactive and post-emergency occurrence measures and plans that will combat disastrous emergencies and their effects head-on. The measures to be adopted should be in line with the nature of the disaster and must conform to the following fundamental principles: Preparedness, Response, Recovery and Mitigation, (McEntire, 2004).

This is to say that measures to be taken to curtail emergencies and their effects from ravaging and ruining the society should be measures taken pre-disaster occurrence in readiness for any eventuality of disastrous nature; measures taken to eliminate, suppress and/or reduce the effects of an already occurred disaster; measures taken to help the victims of disaster as at the time of disaster occurrence in terms disaster rescue; and measures taken to normalize the disaster affected area as well as disaster affected victims.

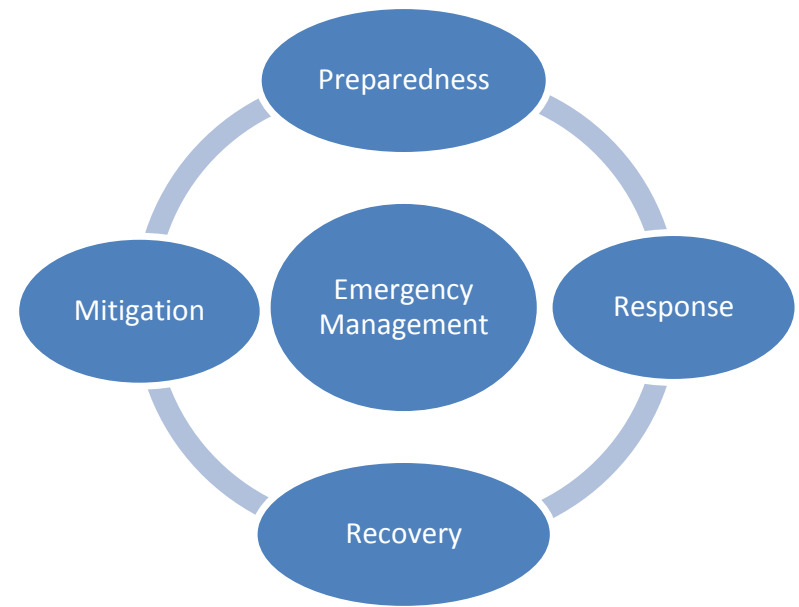

Figure 1: Diagram of the Principles of Emergency Management

\section{APPLICATION OF PRINCIPLES OF EMERGENCY MANAGEMENT THEORY IN THE MANAGEMENT OF COVID 19 PANDEMIC IN NIGERIA}

The four principles of Emergency Management Theory are Preparedness, Response, Recovery and Mitigation, these principles are analysed in line with the Federal Government of Nigeria's measures of managing COVID-19.

Preparedness

This is the planning phase of emergency management where government agencies establish contingency plans to be activated when disaster happens. The contingency plan should of necessity include a hierarchy of command and control, functions and responsibilities and division of activities between agencies and department.

Preparedness also involves human behavior modification so as to limit the effects of disaster events on people. Different strategies might be utilized here such as public education/enlightenment, and drills. Preparedness is a continuous cycle of activities that include planning, managing, controlling, organizing, training, equipping, monitoring, and evaluating to ensure effective coordination and enhancement of the capabilities of organizations involved in emergency management. Preparedness is proactive rather than reactive. In its basic elements it is the anticipation of events 
before they occur and taking steps to ameliorate their impacts when they happen.

In preparation against COVID-19, The Nigeria government through the National Orientation Agency and National Emergency Management Agency embarked on massive awareness and sensitisation campaign on what COVID-19 entails and how citizens can protect themselves and keep safe (UN News, 2020 \& UNICEF, 2020). Also the experience of Nigeria from the outbreak of Ebola disease greatly prepared the country on how to tackle COVID-19 (Onyedinefu, 2020). Outbreaks of yellow fever, monkey pox, laser fever and Ebola also prepared Nigeria to anticipate the challenge of maintaining essential health systems during a response (Prevent Epidemic, 2020). Prior to the confirmation of the first case in Nigeria, Nigeria Center for Disease Control (NCDC) with support from its partners, began preparedness activities. The NCDC began working with states and hospitals to map out and establish isolation and treatment centres for managing COVID-19 cases. In addition to this, NCDC began training health workers across all states on case management, infection prevention control (IPC), surveillance, risk communication and other areas of epidemic preparedness and response. Importantly, NCDC developed preparedness guidelines and plans that incorporated an all-inclusive 'One Health' approach (NCDC, 2021). The treatment and isolation centres created for treatment and isolation of Ebola disease patients were equipped and prepared for COVID-19 purposes. The Nigeria Centre for Disease Control was already studying the outcome of the COVID-19 in other countries before it spread into Nigeria (UNICEF, 2020).

Response

This is the stage where the prepared plans are activated. When an emergency has occurred, government agencies have to move into a response phase where they mobilize resources and execute their plan. Gaps in the planning or preparatory stage may cause an agency to improvise some aspects of their response. This may be due to the nature of the disaster or the socio-economic nature of the community. The response phase calls for the mobilization of the necessary emergency services and first responders in the disaster area.

A well-rehearsed emergency plan developed as part of the preparedness phase enables efficient coordination of rescue. If victims are trapped in collapsed buildings as in the case of earthquake or plane crash, search and rescue operations should begin immediately. It might be necessary to bring in specialized equipment such as cranes, bulldozers etc. to assist in the search and rescue. There is need to build an effective leadership in response to a disaster (Lamidi \& Benson, 2014). A sort of Marshall Plan is needed where leadership formulates and implements effective response plans, adapting to new developments and changes in circumstances as they arise. The management of information is crucial in the response phase. Leadership must ensure that accurate and timely information is released to the public so that tensions can be doused and those affected by the disaster such as family members of victims do not panic. The media can play a crucial role here by ensuring that news coverage do not wipe-up sentiments and induce unnecessary fear in the public domain.

In applying the principle of response to the Federal Government management strategies against COVID-19, the government established the Presidential Task Force on COVID 19, headed by the Secretary to the Federal Government, Boss Mustapha to work in collaboration with the Nigeria Centre for Disease Control (NCDC) and the Federal Ministry of Health (PTF, 2020); Banned all international flights, except for emergency and essential flights (Oyebade, 2020), imposed a lockdown of nonessential activities (Mondaq, 2020); banned interstate travel except for essential needs; banned gatherings of more than twenty persons outside of a workplace; established laboratories for the testing of COVID-19, (NCDC, 2020); and involved Public Private Partnership (PPP) against COVID-19 pandemic (Signé, 2020). The Presidential Task Force on COVID-19 has been giving a daily update of COVID-19 in the country to keep the public informed and curtail fake news and panic.

Recovery

Following an effective response, agencies may then undertake recovery operations in the wake of a disaster. Agencies can assist in the clear- up from the incident, embark on search and rescue and generally, help the people involved overcome their mental trauma. Psychologists, counsellors, and religious persons may be brought in to speak to the people that are affected by a disaster and offer consolatory words and encouragement (McEntire, 2004).

The objective of the recovery phase is to help an affected area to be restored to its previous state and help victims return to their normal lives or better living. The difference between the response phase and recovery is that the latter 
phase is concerned with issues that have been thrown up by the disaster, and these issues must be addressed after the initial needs assessment. Depending on the type of disaster, recovery may be accompanied by efforts such as providing water, food and shelter to those affected by the disaster. Other efforts may involve rebuilding destroyed properties, providing employment, and rebuilding damaged infrastructure. Experts recommend the "build back better" approach, to reduce the predisaster risks inherent in the community and infrastructure. It is pertinent to note that the recovery phase can provide a rare opportunity for authorities to introduce a public policy or programme that might otherwise be unpopular or resisted in normal times. When a disaster is fresh in people's memory, they are more likely to accept negative palliatory measures than otherwise.

In applying the principle of recovery into Federal Government's management of COVID-19 in Nigeria, the government embarked on Gradual ease of lockdown of the economy (BBC News, 2020 and Okwumbu, 2020). The government through PPP and Federal Ministry of Humanitarian Affairs, Disaster Management and Social Development also embarked on provision of unconditional money transfer to poor households and the vulnerable and provided food items as palliatives to the poor and vulnerable (CACOVID, 2020 and Reliefweb, 2020). Passage of the Emergency Economic Stimulus Bill by the House of Representative (Esuga, 2020). The NCDC, Federal Ministry of Health, Nigerian Television Authority (NTA) and other government agencies are constantly encouraging (through jingles, on conventional and social media) Nigerians that the contact of COVID-19 is not a death sentence and that people should still adhere to the COVID-19 health protocols.

Mitigation

The final phase in emergency management is mitigation, which involves taking steps to ensure no reoccurrence is possible. In the case of natural disasters, predicting future occurrence may be less likely. However, plans could be put in place to ensure that less damage is done in the future. The mitigation phase should involve a sort of evaluation of the preceding phases to plug loop-holes and strengthen contingency plans. The result of such evaluation could then be used as feedback and linked to the preparedness stage with updated plans and strategies to deal with future emergencies, thus completing the circle (McEntire, 2004).
Mitigation efforts also present opportunities in emergency management to prevent hazards from developing into disasters. In the cases of tsunamis, hurricanes, and typhoons, weather forecasting technologies have significantly improved to the point of providing early- warning signals, but not prevention. The difference between the mitigation phase and the other phases is that mitigation advocates the adoption of long-term measures for reducing or eliminating risk.

In the application of the mitigation phase of the Emergency Management Theory; the Nigeria Centre for Disease Control (NCDC), Federal Ministry of Health and Public Private Partnership in respect of COVID-19 have continued their awareness and sensitization campaign on personal hygiene and the government is planning on revamping the health care sector of the country. Nigerian researchers are working on developing a vaccine for the disease in the country (Africa Check, 2020). The Federal Government of Nigeria has released $\mathrm{N} 10$ billion through the Ministry of Finance in support of research into the development of COVID-19 vaccine in Nigeria (Premium Times, 2021); Approval of 17 million dollars by the Federal Government for the establishment of oxygen plants across the 36 states and Federal Capital Territory in Nigeria (Fisayo-Babbi, 2021); The government also enacted the COVID-19 Health Protection Regulations Law 2021 (NCDC, 2021); improved and expanded checking facilities and introduced a robust entry measures on all entry points (land boarders, seaports and airports) into the country. The Nigerian government in addition purchased and are currently administering Covid19 vaccines to citizens in the country (Shuaibu 2021 and UNICEF 2021).

The preparation, response, recovery and mitigation measures of Federal Government in managing COVID-19 in Nigeria has helped to reduce the negative effect of the disease in the country, as stated by Corona Tracker (2020), the fatality rate of COVID-19 in Nigeria is about 1.9\% and the recovered rate is $86 \%$, this shows that the disease has been relatively well managed in the country. In the same vein, Andrew (2020) states that the NCDC have been investing in epidemic preparedness for the past three years and has helped to set up public Health Emergency Operations Centres in almost all the states in the country, which has been effective in curtailing the spread of COVID-19 in Nigeria. Also the Nigeria Minister of Health at the daily briefing of the Presidential Task force on COVID- 
19 stated that the percentage rate of COVID-19 in Nigeria is very low compared to countries from other climes (PTF, 2020).

According to The Conversation (2020), the management of COVID-19 by the Federal Government has brought improvement to the health sector, and the reported confirmed and mortality rate due to COVID-19 was lower than other countries with dense urban populations and similar socioeconomic challenges like Nigeria. The table below also indicated that the percentage rate of death from confirmed cases is $1.3 \%$ (very low), percentage rate of recovered cases from confirmed cases is $97.5 \%$ (very high), percentage rate of active cases from confirmed cases is 1.2 (very low) and percentage rate of confirmed cases from sampled tested is $7.8 \%$ (very

low).

Table 1: COVID-19 Cases in Nigeria as at 3 June, 2021

\begin{tabular}{|l|l|l|l|l|}
\hline Samples Tested & Confirmed Cases & Discharged Cases & Active Cases & Death \\
\hline $2,133,061$ & 166,682 & 162,521 & 2,004 & 2,117 \\
\hline
\end{tabular}

Source: NCDC, 2021

\section{EMERGENCY MANAGEMENT THEORY: CRYSTALIZING THE UNCOVERED GROUND}

Some of the loopholes inherent in The Emergency Management Theory are as below: Exclusion of the Concept of Sustainability: A theory on emergency management that excludes measures to save the present and protect the future which are the contents of sustainability is regarded as incomplete (Smith \& Wenger. 2007). It was noted by scholars that the disaster losses are rising exponentially each decade, thus, the limits of preparedness were recognised as not including sustainability among the principles of Emergency Management Theory (Smith \& Wenger. 2007).

Exclusion of the Concept of Vulnerability and Resilience: The exclusion of the concept of vulnerability in the emergency management approach has been declared a great error, because vulnerability, unlike hazards, is undoubtedly the only thing we really have control over in the disaster equation (Kamien, 2006). Thus, the concept of vulnerability may help us better describe and comprehend the true nature of emergencies. Our physical location and infrastructure may make us vulnerable to disasters. Or, our culture, economic conditions, political system, and weak emergency management institutions can bring disaster upon us and constrain how we react to them. Activities during the mitigation and recovery phases of disaster may obviously increase or decrease vulnerability (e.g., locating or rebuilding in less hazardous areas). Vulnerability may also help us to understand the purpose of emergency management since it deals with the goals of liability reduction and capability enhancement (i.e., reducing risk and susceptibility, and raising resistance and resilience) (Kamien, 2006). Not studying who and what is to be affected by an emergency is a deficit of the Emergency Management Theory.

Exclusion of Improvisation alongside Preparedness: The bias in the emergency management theory toward a preparedness model, and away from one that explicitly develops improvisation, is evidenced in the paucity of improvisation training available to emergency managers and in the primacy of planning provided in doctrinal documents (Waugh \& Streib, 2006). Responders examine, validate, and verify the assumptions into facts based upon what they encounter at the time. If any or all of the assumptions are invalidated, the only recourse is to improvise. It is a mistake to assume that a response can be completely scripted. There are indications that, especially under high stress and emergency conditions, humans do not analyze their options rationally and then choose the best solution, humans are able to satisfice, intuit, and improvise (Webb \& Chevreau, 2006). Individuals in high-reliability organizations cope with unexpected events by adapting to circumstances rather than depending on plans. It may be, therefore, that human nature is biased toward improvised solutions over plans in crisis situations (Webb \& Chevreau, 2006).

\section{FINDINGS}

From the examination of the application of the Principles of Emergency management theory in Federal Government's management of COVID19 in Nigeria, the study found that COVID-19 is an emergency because the disease conforms to key baseline conclusions which have emerged from disaster anthropology over past decades. The study also found that the Nigeria Federal Government have utilized the principles of 
Emergency Management Theory in its management of COVID-19 in Nigeria:

In the area of Preparedness, The Federal Government through the National Orientation Agency and National Emergency Management Agency embarked on massive awareness and sensitisation campaign on what COVID-19 entails and how citizens can protect themselves and keep safe. Also the experience of Nigeria from the outbreak of Ebola disease greatly prepared the country on how to tackle COVID-19. The outbreak of infectious disease such as yellow fever, monkey pox, and Ebola prepared Nigeria to anticipate the challenge of maintaining essential health systems during a response. The Nigeria Centre for Disease Control was already studying the outcome of the disease in other countries before it spread into Nigeria.

In applying the principle of Response to the Federal Government management strategies against COVID-19, the government established the Presidential Task force on COVID 19, headed by the Secretary to the Federal Government; Boss Mustapher to work in collaboration with the Nigeria Centre for Disease Control (NCDC) and the Federal Ministry of Health; Banned all international flights, except for emergency and essential flights, imposed a lockdown of nonessential activities; banned interstate travel except for essential needs; banned gatherings of more than twenty persons outside of a workplace; established laboratories for the testing of COVID-19, and involved Public Private Partnership against COVID-19 pandemic, which has been involved in contact tracing. The Presidential Task Force on COVID-19 has been giving daily update of COVID-19 in the country to keep the public informed and curtail fake news and panic.

In applying the principle of recovery into Federal Government's management of COVID-19 in Nigeria, the government embarked on Gradual ease of lockdown of the economy. The government through PPP and Federal Ministry of Humanitarian Affairs, Disaster Management and Social Development also embarked on provision of unconditional money transfer to poor households and the vulnerable and provided food items as palliatives to the poor and vulnerable; passage of the Emergency Economic Stimulus Bill by the House of Representative. The NCDC, Federal Ministry of Health, Nigerian Television Authority (NTA) and other government agencies are constantly encouraging (through jingles, on conventional and social media) Nigerians that the contact of COVID-19 is not a death sentence and that people should still adhere to the COVID-19 health protocols.

In the area of Mitigation phase of the Emergency Management Theory; the Nigeria Centre for Disease Control (NCDC) and Federal Ministry of Health, Public Private Partnership in respect of COVID-19 have continued their awareness and sensitization campaign on personal hygiene and improving the health care sector of the country. The government have improved and expanded checking facilities on all entry points into the country like land boarders, seaports and airports.

The study also found that the Emergency Management theory has some pitfalls which are: exclusion of the concepts of sustainability, vulnerability, resilience and improvisation in its principles.

\section{CONCLUSION}

The study concludes that the adoption of the principles of Emergency Management Theory in the management of COVID-19 in Nigeria has greatly enhanced the Federal Government's efforts in the fight against the disease in Nigeria thus leading to a low percentage of fatality and confirmed cases of COVID-19 in the country.

\section{RECOMMENDATIONS}

To improve on the utilization of the principles of Emergency Management Theory in emergency management in Nigeria, especially as it affects diseases outbreak, the study made the following recommendations:

a. Individual Researchers and institutions should be supported by government and nongovernment organisations to develop more proactive ways of dealing with disease outbreaks and related emergencies in the country.

b. Federal Ministry of Humanitarian Affairs, Disaster Management and Social Development and other response agencies should coordinate resources properly towards efficient and effective disaster prevention, preparedness, mitigation and response in the country.

c. Emergency management agencies in the country should study and include the concepts of sustainability, vulnerability and improvisation in their emergency management strategies to enhance their activities towards emergency situations.

d. Emergency management practices that are in tune with our culture, belief and values should be studied for improvement on how to control people during an emergency. Proactive policies to minimize human-caused emergencies should be formulated by Nigerian legislators. 
e. Nigerians should all be orientated and sensitized on how to prevent, respond and deal with emergencies, which will go a long way in helping to avert some of the negative effects of emergencies in the country.

f.

\section{REFERENCES}

Africa Check., 2020. Nigeria and COVID-19: Fact-checking Claims About Vaccines and Lack of Research. https://africacheck.org/reports

Andrew, W., 2020. What the US Could learn from Nigeria's Response to the Covid-19 Coronavirus Outbreak. https://www.forbes.com

BBC News., 2020. Coronavirus: Nigeria to ease Abuja and Lagos lockdowns on 4 May. https://www.bbc.com/news/world-africa52445414

CACOVID 2020. Staying Alive Together. (https://www.cacovid.org/) Callaway E., 2020. Time to use the p-word? Coronavirus enter dangerous new phase. Nature: 579.

Cambridge Dictionary 2020. Emergency. https://dictionary.cambridge.org/dictionar y/english/emergency

Corona Tracker 2020. Nigeria overview. https://coronatracker.com/analytics

Esuga, S., 2020. Nigeria's Emergency Economic Stimulus Bill in Response to The COVID19 Pandemic. https://www.mondaq.com/nigeria/employ ment-and-workforcewellbeing/917746/nigeria39s-emergencyeconomic-stimulus-bill-in-response-tothe-covid-19-pandemic

Ezenyilimba, E., Mmaduagwu, N. E., and Eze, J. O., 2018. Disaster Management in a Volatile Ecowas Region: Nigerian Perspective. International Journal of Academic Research in Economics and Management Sciences. 7(3).

Fisayo-Bambi, J., 2021. Nigeria to build 38 Oxygen plants as treatment centres struggle with COVID patients. https://www.africanews.com/2021/01/22/ nigeria-to-build-38-oxygen-plants-astreatment-centres-struggle-with-covidpatients//

Haddow, G. D. and Bullock, J. A., 2013. International Disaster Management. New York: Random House Inc.

Kamien, D. G., 2006. The McGraw Hill Homeland Security Handbook, New York: McGrawHill

Kelman. I., 2020. COVID-19: What is the Disaster? European Association of Social Anthropology.

https://www.preventionweb.net/publicatio ns/view/72455

Khorram-Manesh, A., 2017. Handbook of Disaster and Emergency Management. Gothenburg Sweden. Kompendiet.

Lamidi, O. K. and Benson, K. S., 2014 "Institutional Need and Relevance of Emergency Management Agency in the Nigerian Local Government System" International Journal of Politics and Good Governance, Vol. 5, No. 5.2, Quarter II, ISSN: $0976-1195$

Mackenzie, J. S. and Smith, D. W., 2020. COVID-19: a Novel Zoonotic Disease Caused by a Coronavirus from China: What we Know and What we Don't. Microbiol Aust. 41(1):45. doi:10.1071/MA20013

McEntine, D., 2004. The status of emergency management theory: Issues, barriers and recommendations for improved scholarship. A paper presented at the Annual emergency management Higher education conference, National emergency training center, Emmetsburg, Maryland.

Mondaq, A. I., 2020. The Federal Government Of Nigeria Has Issued COVID-19 Regulations, 2020. https://www.mondaq.com/nigeria/operati onal-impacts-and strategy/919666

Nigeria Centre for Disease Control (NCDC), 2020. COVID-19 Laboratories. https://covid19.ncdc.gov.ng/state/ 
Nigeria Centre for Disease Control NCDC, 2021. Coronavirus Disease (Covid-19) Health Protection Regulations 2021. https://covid19.ncdc.gov.ng/media/files/C oronavirus-Disease-COVID19-HealthProtection-Regulations-2021.pdf

Nigeria Centre for Disease Control NCDC, 2021b. One Year of COVID-19 Response in Nigeria. https://ncdc.gov.ng/news/324/one-yearof-covid-19-response-in-nigeria

Nigeria Centre for Disease Control NCDC, 2021. NCDC Coronavirus Covid-19 Microsite. https://covid19.ncdc.gov.ng

Ogbonna A. C., 2020. Coronavirus: The Economics of the Pandemic and Performance of the Nigeria Economy. African Journal of Biology and Medical Research. Volume 3, Issue 2.

Okwumbu, R., 2020. FG extends phase 2 of eased COVID-19 lockdown by one week. https://nairametrics.com/2020/07/27/justin-fg-extends-phase-2-of-eased-covid19-lockdown/

Onyedinefu, G., 2020. How Ebola experience is helping Nigeria fight COVID-19. https://businessday.ng/health/article/howebola-experience-is-helping-nigeria-fightcovid-19/

Oyebade, W., 2020. International flights grounded, ban on foreign travellers takes effect. https://guardian.ng/news

Premium Times, 2021. COVID-19: Nigeria releases N10 bn for vaccine production. https://www.premiumtimesng.com/news/headl ines/437243-covid-19-nigeria-releases-n10bn-for-vaccine-production.html

Presidential Task Force (PTF) on COVID-19 $2020 . \quad$ About PTF. https://statehouse.gov.ng/covid19/

Prevent Epidemics. 2020. COVID19/ Success in Action. https://preventepidemics.org/stories/beyo nd-covid-19-nigerias-efforts-to-balancethe-pandemic-response/
Relief web 2020. Nigeria Situation

Report.

https://reliefweb.int/report/nigeria/nigeriasituation-report

Shuaibu, I. B., 2021. Nigeria: Leaders Get Covid$19 \mathrm{Jab}$ to Encourage Citizens. https://www.aa.com.tr/en/africa/nigerialeaders-get-covid-19-jab-to-encouragecitizens/2167715

Sinha, A. and Srivastarv, R., 2017. Concept, Objectives and Challenges of Disaster Management. International Journal of Science and Research. 6(7).

Smith, G. P., and Wenger, D., 2007. Sustainable Disaster Recovery. In H. Rodriguez, E. Quarantelli, and R. Dynes (Eds.), Handbook of Disaster Research. Springer.

The Conversation 2020. Getting to Grip With the COVID-19 Outbreak in Nigeria. https://theconversation.com

Udouko, O. D., 2017. "Emergency Preparedness and Response - Ideal Perspective" A Paper presented at a workshop on enhancing Disaster Risk Management in Akwa Ibom State, Nigeria

UN News., 2020. Nigeria: UN and partners acting to avert coronavirus spread in displacement camps. https://news.un.org/en/story/2020/04/106 0812

UNICEF, 2020. The unsung early heroes of the battle against COVID-19 in Nigeria. https://www.unicef.org/nigeria/stories/uns ung-early-heroes-battle-against-covid-19nigeria

UNICEF, 2021. Covid-19 Vaccines Shipped; Covax Arrive Nigeria.

https://www.unicef.org/nigeria/pressreleases/covid-19-vaccines-shippedcovax-arrive-nigeria.

Vaccinateyourfamily 2021. Vaccines and Diseases. https://vaccinateyourfamily.org/vaccinesdiseases/?acc=COVID-19

Waugh, W. L. and Streib, G., 2006. Collaboration and leadership for effective emergency 
management. Public Administration Review, 66(s1).

Webb, G. R. and Chevreau, F. R., 2006. Planning to improvise: The Importance of creativity and flexibility in crisis response. International Journal of Emergency Management, 3(1).

World Health Organization WHO, 2020a. Coronavirus disease COVID-19 Pandemic.

https://www.who.int/emergencies/disease s/novel-coronavirus-2019?
World Health Organization WHO, 2020b. Humanitarian Health Action. Definitions: emergency.

https://www.who.int/hac/about/definitions/ en

World Population Review 2021. Nigeria Population 2021. http://worldpopulationreview.com/countri es/nigeria/

Yemisi, O. I., 2020. COVID-19 Pandemic and Social Protection Conundrum in Nigeria. DOI: 10.13140/RG.2.2.17418.62403. 